\title{
Covid-19: medical students and FY1 doctors to be given early registration to help combat covid-19
}

\author{
Anna Harvey
}

The BMJ

Final year medical students are to be offered early provisional registration and foundation year 1 (FY1) doctors early full registration with the General Medical Council to help staffing levels during the covid-19 pandemic, a joint statement from regulatory and training bodies released on 25 March says. ${ }^{1}$

The statement from the UK health departments, the GMC, Health Education England, NHS Education for Scotland, Health Education and Improvement Wales, the Northern Ireland Medical and Dental Training Agency, and the Medical Schools Council states that final year medical students who have been deemed by their medical school to have met the GMC's outcomes for graduates ${ }^{2}$ can graduate early.

Medical schools are to work with the Medical School's Council to accelerate assessing these competencies where possible, to facilitate students joining the workforce as soon as is practical. For these students, there will be an "opt-in" system allowing them to secure early provisional registration and start work in new FY1 locum roles. ${ }^{3}$ The roles are required by the GMC to have adequate induction, supervision, and availability of personal protective equipment. ${ }^{4}$

BMA Junior Doctor Committee chair Sarah Hallett said:

"Medical students who are provisionally registered and become junior doctors at this unprecedented time for the NHS must be guaranteed comprehensive induction and supervision, particularly in the difficult circumstances under which they are joining.

"It's crucial we ensure that our colleagues are well supported as they join the NHS workforce, and that they are equipped to cope with the challenges facing our health service now, as well as developing the skills to be valuable members of the workforce for decades to come."

FY1 doctors will have an accelerated timeline to convert their current provisional registration to full registration, provided they can secure a certificate from their trust stating that they have achieved the GMC's Outcomes for Provisionally Registered Doctors. ${ }^{5}$

As a fully registered doctor, trainees can practise with less supervision, including a wider range of prescribing responsibilities and, in some areas, the ability to independently discharge patients from hospital care. Trainees who are granted full registration will remain in their current FY1 posts to ensure continuity of support. "Assurances of continued clinical and educational supervision should be in place for these doctors to enable them to take increasing responsibility for patient care," the statement says.

Health Education England. Joint statement from the UK Health Departments, the General Medical Council, Health Education England, NHS Education for Scotland, Health Education and Improvement Wales, the Northern Ireland Medical and Dental Training Agency, and the Medical Schools Council. 25 March 2020. www.hee.nhs.uk/sites/default/files/ documents/Joint\%20statement\%205th\%20year\%20medical\%20students_0.pdf.

2 General Medical Council. Outcomes for graduates plus supplementary guidance. www. gmc-uk.org/education/standards-guidance-and-curricula/standards-and-outcomes/ outcomes-for-graduates.

3 BMA. COVID-19: early provisional registration for final year students. 2020. https://beta. bma.org.uk/advice-and-support/covid-19/your-contract/covid-19-early-provisionalregistration-for-final-year-students.

4 Harvey A. Covid-19: medical schools given powers to graduate final year students early to help NHS. BMJ 2020;368:m122710.1136/bmj.m1227.

5 General Medical Council. Outcomes for provisionally registered doctors. www.gmc-uk. org/education/standards-guidance-and-curricula/standards-and-outcomes/outcomes-forprovisionally-registered-doctors

Published by the BMJ Publishing Group Limited. For permission to use (where not already granted under a licence) please go to http://group.bmj.com/group/rights-licensing/ permissions 